\title{
CONF-95/155--104
}

\section{MOCVD OF VERY THIN FILMS OF LEAD LANTHANUM TITANATE}

\author{
DAVID B. BEACH, CATHERINE E. VALLET \\ Chemical and Analytical Sciences Division, Oak Ridge National Laboratory, Oak Ridge, TN 37831- \\ 6197, beachdb@oml.gov
}

\section{ABSTRACT}

Films of lead lanthanum titanate were deposited using metal-organic chemical vapor deposition (MOCVD) at temperatures between 500 and $550^{\circ} \mathrm{C}$ in a hot-wall reactor. The precursors used were $\mathrm{Pb}(\mathrm{THD})_{2}, \mathrm{La}(\mathrm{THD})_{3}$, and $\mathrm{Ti}(\mathrm{THD})_{2}(\mathrm{I}-\mathrm{OPr})_{2}$ where $\mathrm{THD}=2,2,6,6$-tetramethyl-3,5-heptanedionate, $\mathrm{O}_{2} \mathrm{C}_{11} \mathrm{H}_{19}$, and I-OPr = isopropoxide, $\mathrm{OC}_{3} \mathrm{H}_{7}$. The three precursors were delivered to the reactor using a single solution containing all three precursors dissolved in tetraglyme and the precursor solution was volatilized at $225{ }^{\circ} \mathrm{C}$. Films were deposited on $\mathrm{Si}$ and Si/Ti/Pt substrates, and characterized using Rutherford Backscattering Spectroscopy (RBS) and X-ray diffraction(XRD). Films deposited at $550^{\circ} \mathrm{C}$ had a composition which was close to that of the precursor solution while films deposited at $500^{\circ} \mathrm{C}$ were deficient in lanthanum. Even at $500^{\circ} \mathrm{C}$, the desired perovskite phase is readily observed by XRD. Subsequent rapid thermal processing of the film deposited at $500{ }^{\circ} \mathrm{C}$ showed an increase in the intensity of the X-ray lines, but did not change the width of these lines, implying that grain sizes had remained unchanged.

\section{INTRODUCTION}

High performance thin-film capacitors are of vital importance in microelectronics. They are used for storage applications such as memory chips and are being used increasingly in microprocessor applications where high speed operation requires the use of on-chip decoupling capacitors. These capacitors consist of a dielectric layer between two conductive electrodes, and materials such as silicon dioxide and/or silicon nitride are usually used. The push to smaller and smaller dimensions decreases the area of the capacitor and thus thinner dielectric layers are used to achieve the required capacitance. Unfortunately, these materials cannot be made infinitely thin before electrons begin to "tunnel" between the electrodes. An alternative to silicon dioxide/nitride dielectrics is to use a dielectric material with a higher dielectric constant.

High dielectric constant materials such as barium titanate, lead titanate, and related compounds with the perovskite crystal structure may have dielectric constants several orders of magnitude higher than silicon dioxide. ${ }^{1}$ These materials have the ability to store a large amount of charge because the cation lattices distort when an electric field is applied. By replacing 28 at. \% of the lead in lead titanate with lanthanum to form lead lanthanum titanate (PLT), the material is no longer ferroelectric (paraelectric), ${ }^{2}$ but still retains a high dielectric constant, and is, therefore, useful for high-speed memory and microprocessor applications. In addition to lowering the transition temperature between ferroelectric and paraelectric behavior, lanthanum substitution also increases the resistivity of the material.

Thin-film paraelectric formulations of PLT have been prepared by a number of techniques including sol-gel, ${ }^{3,4}$ physical vapor deposition ${ }^{5}$ and MOCVD. ${ }^{6}$ We have recently made a study of sol-gel prepared thin-films in the thickness range of 300 to $2000 \AA$ and determined the following: 1) the dielectric constant decreases significantly with decreasing thickness, 2) the leakage current increases with decreasing thickness, 3) prolonged annealing leads to degradation of electrical properties, presumably due to interfacial reactions of the dielectric film and the noble metal electrode, 4) optimum thickness was found to be $-1000 \AA$, yielding a dielectric constant of 600 and 


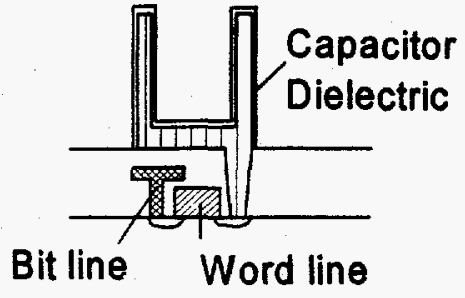

Figure 1. Stack capacitor structure. a leakage current less than $1 \times 10^{-8} \mathrm{~A} / \mathrm{cm}^{2}$ at 1 volt.

One figure of merit for an insulator in DRAM applications which takes into account both film thickness and dielectric constant is the capacitance per unit area, expressed in $\mathrm{FF} / \mu \mathrm{m}^{2}$. The requirement for 1 gigabit DRAM is likely to be in excess of $100 \mathrm{fF} / \mu \mathrm{m}^{2}$, while the best results obtained for PLT in our sol-gel work are in the range of $50 \mathrm{fF} / \mu \mathrm{m}^{2}$. Therefore, it is likely that the area available for the deposition of the capacitor will need to be increased by at least a factor of 2 . One method currently used for increasing capacitor area is the use of a "stack" on top of the transistor of the memory cell. This is depicted in Figure 1. To construct such a structure, it will be necessary to conformally coat the stack structure. This is best accomplished using a CVD process.

This paper reports preliminary studies on MOCVD of PLT. The goals of this work are to deposit PLT in the thickness region of 600 to $1000 \AA$, and to minimize the degradation of the electrode by depositing at low temperatures and using rapid thermal processing .

\section{EXPERIMENTAL}

The reactor used in this study is depicted in Fig. 2. Precursors, dissolved in solvent, were metered using an Eldex Model A-120-S liquid metering pump designed for use in liquid chromatography. For the metering pump to work correctly, it was necessary to insert a back-pressure regulator which consisted of a valve held in its seat by a spring. A pressure of $\sim 30 \mathrm{psig}$ was required to open the valve. Oxygen was allowed to flow around the tube carrying the solution to prevent sublimation

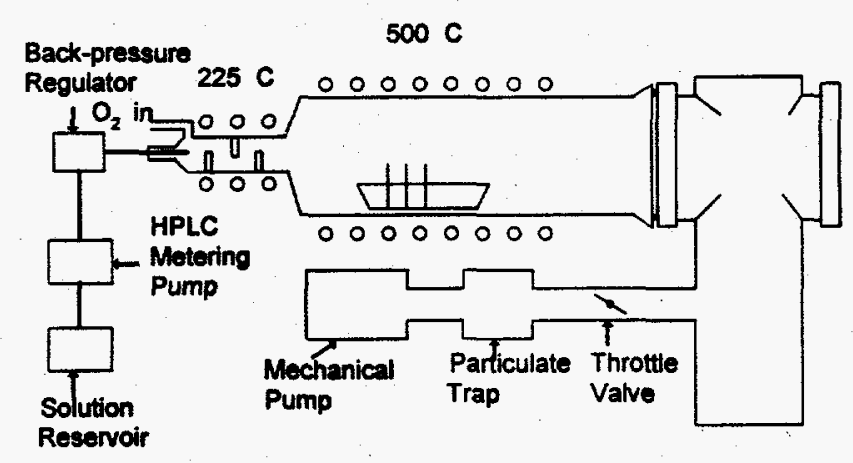

Figure 2. Hot-wall MOCVD system with liquid precursor delivery system.

of precursor in the upstream direction. The metered solution entered the evaporator which was constructed of 1 inch diameter quartz tubing with several baffles to prevent transport of droplets into the main reactor. The evaporator was heated externally by a tube furnace held at about $225^{\circ} \mathrm{C}$. This 
temperature was as low as possible to prevent premature solvent evaporation or precursor decomposition. The main reactor consisted of a 3 inch diameter quartz tube heated by a three-zone electric tube furnace. A throttle valve in the pumping line allowed a constant reactor pressure independent of the flow settings.

The lead precursor used in this study was lead bis(2,2,6,6-tetramethyl-3,5-heptanedionate), $\mathrm{Pb}(\mathrm{THD})_{3}$, (StremChemicals) and was purified by sublimation at $145^{\circ} \mathrm{C}$ at $10^{-1}$ torr. The lanthanum precursor was lanthanum tris(2,2,6,6-tetramethyl-3,5-heptanedionate), $\mathrm{La}(\mathrm{THD})_{3}$, (StremChemicals) which was also purified by sublimation at $210^{\circ} \mathrm{C}$ at $10^{-1}$ torr. The titanium precursor was titanium bis(isopropoxide)-bis(2,2,6,6-tetramethyl-3,5-heptanedionate), $\mathrm{Ti}(\mathrm{iOPr})_{2}(\mathrm{THD})_{2}$, which was synthesized by the method of Gardiner et al., 7 and sublimed before use at $150^{\circ} \mathrm{C}$ at $10^{-1}$ torr. All three compounds were dissolved in tetraglyme (tetraethylene glycol dimethyl ether).

Substrates used in this study were Si wafers for RBS compositional analysis and $\mathrm{Si} / \mathrm{SiO}_{2}(2000$ $\AA) / \mathrm{Ti}(200 \AA) / \mathrm{Pt}(1000 \AA)$ for XRD film structure analysis. Si substrates were degreased and dipped in $10 \% \mathrm{HF}$ until hydrophobic. Platinum coated substrates were ashed in an oxygen plasma.

Typical deposition conditions were as follows:

Precursor solution: 0.30 molar in $\mathrm{Ti}_{(\mathrm{iOPr}}(\mathrm{THD})_{2}, 0.23$ molar in $\mathrm{Pb}\left(\mathrm{THD}_{2}\right.$, and 0.084 molar in $\mathrm{La}(\mathrm{THD})_{3}$ in tetraglyme.

Precursor solution delivery rate: $0.5 \mathrm{ml} / \mathrm{min}$

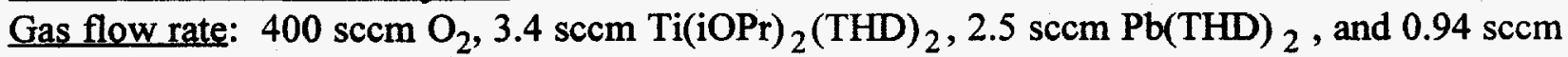
$\mathrm{La}(\mathrm{THD})_{3}$.

Reactor pressure: 1.5 torr

Film growth rate: $\sim 60 \AA / \mathrm{min}$ at $500^{\circ} \mathrm{C}$.

\section{RESULTS AND DISCUSSION}

\section{Deposition Process}

All three precursors were found to be reasonably soluble in tetraglyme. Tetraglyme was chosen for use as the solvent because of its low volatility and high temperature stability. It is important that the solvent not evaporate too quickly, or plugging of precursor inlet tube may occur. It is also important that the solvent not readily oxidize in the evaporator region of the apparatus. In fact, tetraglyme appeared to transport through the reactor essentially unchanged at temperatures of 500 to $550^{\circ} \mathrm{C}$. An unexpected benefit of the use of tetraglyme was that it appeared to aid the transport of the $\mathrm{La}(\mathrm{THD})_{3}$. This materials sublimes only slowly at $210^{\circ} \mathrm{C}$, but was transported at temperatures as low as $180^{\circ} \mathrm{C}$ when dissolved in tetraglyme. This may imply some form of adduct formation, although no studies of adduct formation were done.

Films produced by this technique were smooth with a surface roughness of less than $20 \AA$ as measured using atomic force microscopy (AFM). The films were not particularly uniform with a $25 \%$ variation of thickness across a distance of 1 inch. Since we believe that the hot-wall configuration should yield uniform wafer temperature, it is reasonable to assume that turbulence in the precursor flow stream is responsible for the nonuniformity.

Observed growth rates of $100 \AA \mathrm{min}$ at $550^{\circ} \mathrm{C}$ and $60 \AA / \mathrm{min}$ at $500^{\circ} \mathrm{C}$ allow reasonable control of the film thickness by varying the deposition time. Future modifications of the reactor will incorporate a means for shunting the precursor flow in order to allow sharper turn-on and turn-off. 


\section{Film Composition}

Film composition was determined using RBS. The technique was found to be nearly ideal for giving composition of PLT films in the thickness range of 500 to $1000 \AA$, and does not require the use of standards. The spectrum of a film deposited at $550^{\circ} \mathrm{C}$ is shown in Figure 3. Analysis of the spectrum indicates that the ratio of $\mathrm{Pb}$ to $\mathrm{La}$ to $\mathrm{Ti}$ was 0.60 to 0.25 to 1.0. The cation ratio in the precursor solution was 0.75 to 0.28 to 1.0 , indicating that the film cation composition is very similar to that of the precursor solution.

When the deposition temperature is lowered to $500{ }^{\circ} \mathrm{C}$, Figure 4 , the analysis of the spectrum indicates a significant deficiency in lanthanumwith a cation ratio of 0.72 to 0.13 to $1.0(\mathrm{~Pb}$ to $\mathrm{La}$ to Ti).

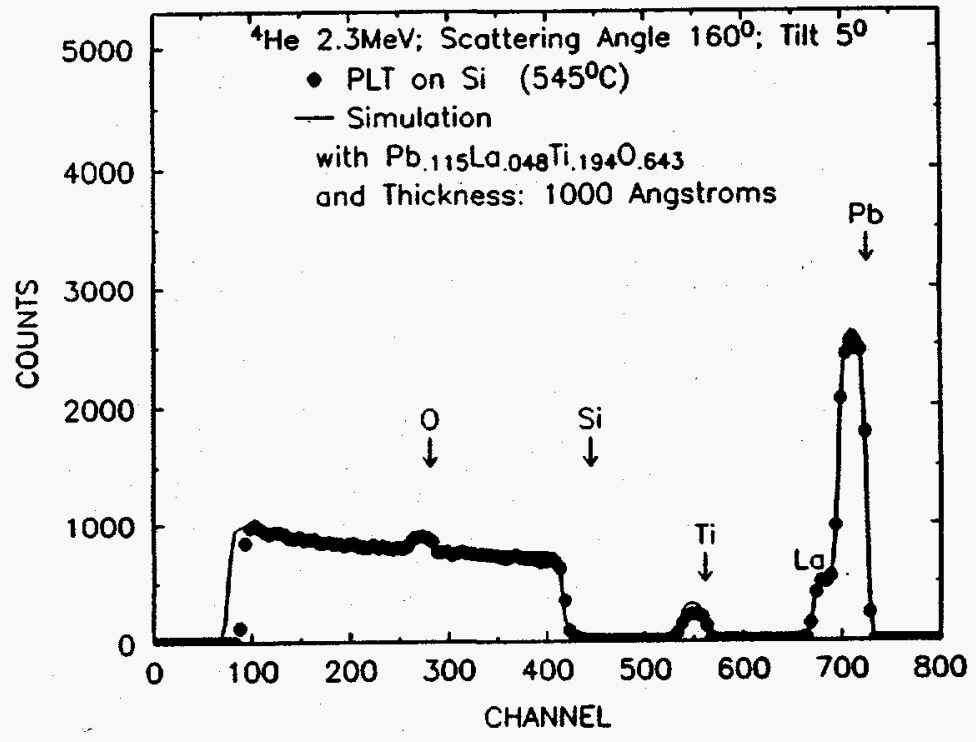

Figure 3. RBS of a $1000 \AA$ thick PLT film on $\mathrm{Si}$.

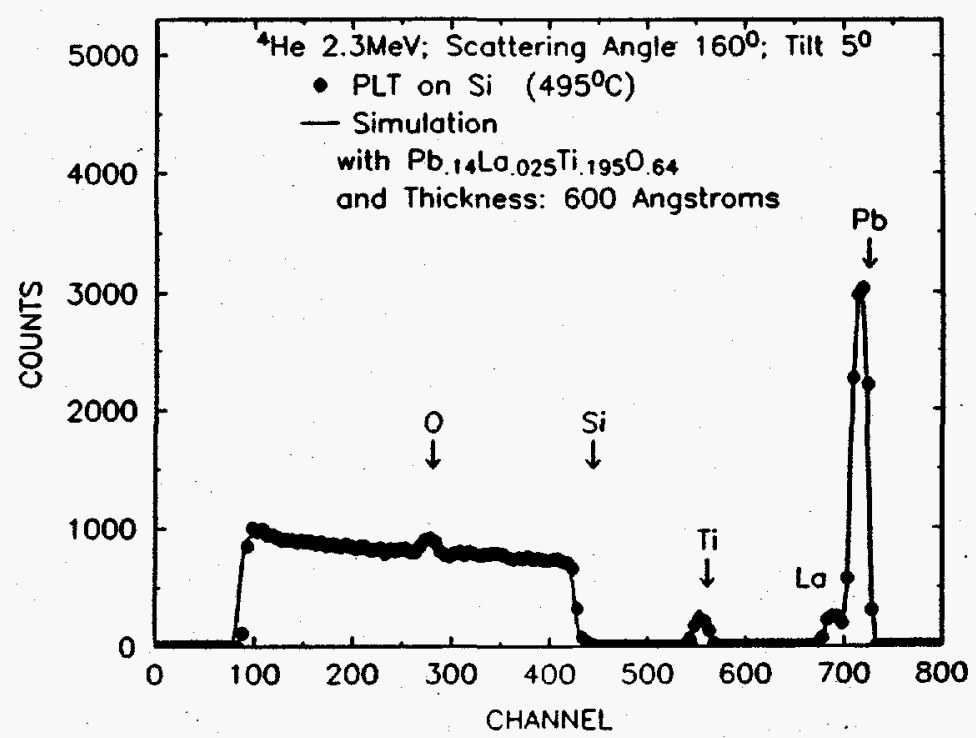

Figure 4. RBS of a $600 \AA$ thick PLT film on Si. 


\section{Film Structure}

Although the film deposited at $500^{\circ} \mathrm{C}$ was deficient in lanthanum as shown in the previous section, it was still desirable to study the effects of rapid thermal processing on the structure of this film. The XRD of the film, both as deposited and after a 1 minute anneal at $700^{\circ} \mathrm{C}$ in a quartz lamp heated rapid thermal processor set to increase the temperature at a rate of $100{ }^{\circ} \mathrm{C} / \mathrm{sec}$, is shown in Figure 5.

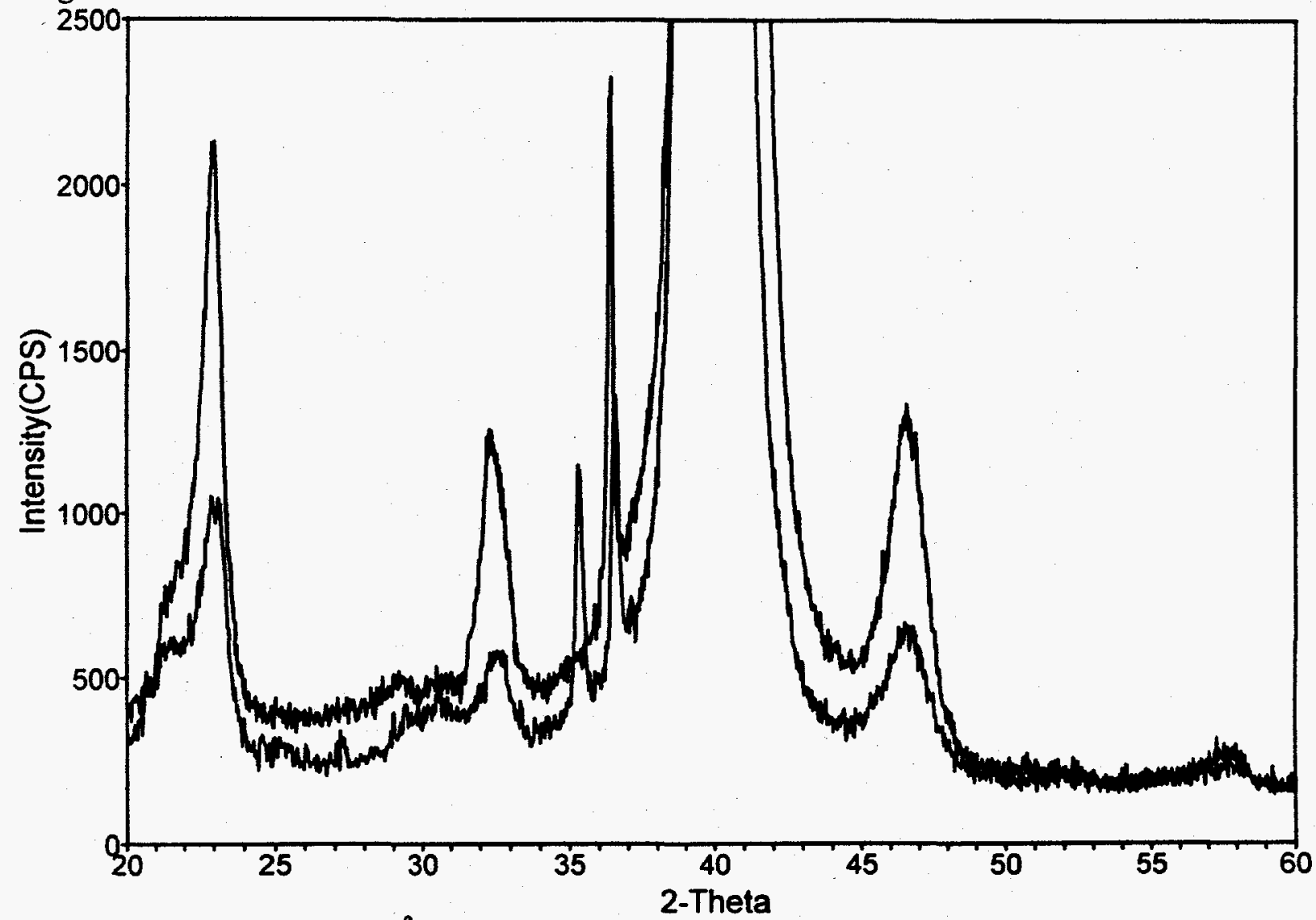

Figure 5. XRD of a $600 \AA$ thick PLT film on a Pt coated Si substrate. The lower trace is the as deposited film while the upper trace is after rapid thermal processing as described in the text. The strong peak $40^{\circ}$ with a satellite at $36.8^{\circ}$ is the $\mathrm{Pt}$ [111] substrate rflection. Peaks at $23^{\circ}, 32.5^{\circ}$, and $47^{\circ}$ correspond to PLT [100], [110], and [200] lines, respectively.

The as-deposited film was crystalline with a preferred [100] orientation. The primary effect of rapid thermal processing was to increase the intensity of all of the line of the spectrum. The full width at half maximum (fwhm) of the lines is essentially unchanged, indicating that grain sizes within the film had remained unchanged.

\section{CONCLUSIONS}

Although these are preliminary results, it is clear that two issues will need to be addressed in subsequent experiment. It is likely that, at $550{ }^{\circ} \mathrm{C}$ and above, film growth may be mass-transport limited, and precursors may decompose at a rate similar to the rate at which they collide with the 
surface (high reactive sticking probability). Thus, the film and precursor solution compositions are very similar, while at $500^{\circ} \mathrm{C}$ and at lower temperatures, surface kinetic processes are dominant (low reactive sticking probability), and some elements may not be incorporated into the film with high efficiency. Unfortunately, to achieve good conformality, it will be necessary to deposit in this temperature range where molecules can undergo many collisions with the surface before decomposition. Therfefore, it will be necessary to vary the precursor solution composition to obtain the correct film composition at a given temperature.

The second issue to address is that of film structure. Our initial goal was to mimic the sol-gel process to the extent that the MOCVD process would be used to prepare a dense, intimately mixed, amorphous, pre-ceramic film which could then be crystallized using rapid thermal processing. However, even at temperatures as low as $500{ }^{\circ} \mathrm{C}$, the films were crystalline. Moreover, unlike in our sol-gel films, ${ }^{4}$ rapid thermal processing had no effect on the size of crystallites, indicating that the grain size was somehow fixed by the MOCVD process. To produce amorphous films, it may be necessary to decrease the deposition temperature, which will undoubtedly further change the composition of the PLT films.

\section{ACKNOWLEDGMENT}

The authors would like to thank Dr. Robert Laibowitz of the IBM Corp. for the gift of platinum coated substrates. The RBS measurements were done at the Surface Modification and Characterization (SMAC) user facility at the Oak Ridge National Laboratory. This work was sponsored by Lockheed Martin Energy Research Corp. for the U.S. Department of Energy under contract DE-AC05-960R22464

\section{REFERENCES}

1. C. Kittel, Introduction to Solid State Physics, 5th ed.; (John Wiley \& Sons, New York, 1976), pp. $399-432$.

2. G. H. Haertling and C. E. Land, J. Amer. Ceram. Soc. 54, 1 (1971).

3. J. J. Lee and S. K. Dey, Ceramic Trans., 25, 235 (1992):

4. D. B. Beach, R. B. Laibowitz, T. M. Shaw, A. Grill and W. F. Kane, Integr. Ferroelectrics, 7, 161 (1995).

5. G. F. Fox, S. B. Krupanidhi, K. L. More, and L. F. Allard, J. Mater. Res., 7, 3039 (1992).

6. P. C. Van Buskirk, J. Roeder, S. Bilodeau, S. Pombrik, and H. Beratan, Integr. Ferroelectrics, 6, 141 (1995).

7. R. A. Gardiner, P. C. Van Buskrik, and P. S. Kilin Mat. Res. Soc. Proc., 335, 221, (1994).

\section{DISCLAIMER}

\footnotetext{
This report was prepared as an account of work sponsored by an agency of the United States Government. Neither the United States Government nor any agency thereof, nor any of their employees, makes any warranty, express or implied, or assumes any legal liability or responsibility for the accuracy, completeness, or usefulness of any information, apparatus, product, or process disclosed, or represents that its use would not infringe privately owned rights. Reference herein to any specific commercial product; process, or service by trade name, trademark, manufacturer, or otherwise does not necessarily constitute or imply its endorsement, recommendation, or favoring by the United States Government or any agency thereof. The views and opinions of authors expressed herein do not necessarily state or reflect those of the United States Government or any agency thereof.
} 